\begin{tabular}{cc}
\hline & Sharif University of Technology \\
Scientia Iranica & Transactions F: Nanotechnology \\
SCIENTIA & www.scientiairanica.com \\
IRAN ICA & \\
\hline
\end{tabular}

\title{
Investigation of carbon phase evolutions in titanium nitride-carbon nanocomposites prepared in supercritical benzene with respect to their lithium storage capacity
}

\author{
E. Yousefia,b,*, M. Ghorbani ${ }^{a, *}$, A. Dolati ${ }^{a}$ and H. Yashiro ${ }^{b}$ \\ a. Department of Materials Science and Engineering, Sharif University of Technology, Tehran, P.O. Box 11155-9466, Iran. \\ b. Department of Chemistry and Bioengineering, Faculty of Engineering, Iwate University, 4-3-5 Ueda, Morioka, Iwate 020-8551, \\ Japan.
}

Received 8 August 2016; accepted 29 October 2016

KEYWORDS
Titanium
nitride-graphene
nanocomposite;
Carbon phase
evolution;
Supercritical benzene;
Li ion battery.

\section{Introduction}

Lithium Ion Batteries (LIBs) with high energy density, long cycle life, and environmentally friendly aspect are important power sources in portable electronics and electric vehicles. Layered structure carbonaceous

\footnotetext{
*. Corresponding authors. Tel.: +98216616 5219;

Fax: +982166005717

E-mail addresses: yousefi@mehr.sharif (E. Yousefi); ghorbani@sharif.edu (M. Ghorbani); dolati@sharif.edu (A. Dolati); yashiro@iwate-u.ac.jp (H. Yashiro)
}

doi: $10.24200 /$ sci. 2017.4417

\begin{abstract}
Titanium nitride-carbon nanocomposites have been synthesized by the reaction of $\mathrm{TiCl}_{4}$ and $\mathrm{NaN}_{3}$ in supercritical benzene medium that also serves as a carbon source. The as-prepared precursor has been subjected to different heat treatments under synthesized TiN-C nanocomposites are studied by X-Ray Diffraction (XRD) and CHN elemental analysis. Meanwhile, the nature of carbonaceous species and the respective phase transitions during supercritical process and following heat treatments are further investigated by Raman spectroscopy, Time of Flight Secondary Ion Mass Spectrometry (ToF-SIMS), and their charge-discharge characteristics with respect to ithium storage. After $10 \mathrm{~h}$ of $\mathrm{NH}_{3}$ treatment at $1000^{\circ} \mathrm{C}$, carbonaceous phase transforms to graphene layered structure. The highly efficient mixed TiN conducting network and the internal defects between $G$ layers induced by nitrogen doping improve rate capability and cycling performance of $\mathrm{G}$ sheets and provide a specific capacity of $381 \mathrm{mAh} \mathrm{g}^{-1}$ at Charge/Discharge (C/D) rate of $0.2 \mathrm{C}$. The enhanced electrochemical performance of the SIV nanocomposite is mainly due to improving the electronic/ionic conductivity, reducing from anchoring of TiN nanoparticles to graphene sheets.
\end{abstract}

(C) 2017 Sharif University of Technology. All rights reserved. 
Table 1. Synthesis and heat treatment conditions.

\begin{tabular}{|c|c|c|c|c|c|}
\hline \multirow[b]{2}{*}{ Sample } & \multicolumn{2}{|c|}{ Synthesis conditions } & \multicolumn{3}{|c|}{ Heat treatment } \\
\hline & $\begin{array}{c}\text { Temperature } \\
\left({ }^{\circ} \mathrm{C}\right)\end{array}$ & $\begin{array}{l}\text { Time } \\
(\mathrm{h})\end{array}$ & Atmosphere & $\begin{array}{c}\text { Temperature } \\
\left({ }^{\circ} \mathrm{C}\right)\end{array}$ & $\begin{array}{c}\text { Time } \\
(\mathbf{h})\end{array}$ \\
\hline SI & 380 & 1 & - & - & - \\
\hline SII & 380 & 8 & - & - & - \\
\hline SIII & 380 & 1 & $\mathrm{NH}_{3}$ & 1000 & 3 \\
\hline SIV & 380 & 1 & $\mathrm{NH}_{3}$ & 1000 & 10 \\
\hline SV & 380 & 1 & $\mathrm{~N}_{2}$ & 1000 & 10 \\
\hline
\end{tabular}

phase can avoid aggregation of the particles and recover electrical connection between the anode particles and the current collector $[5,6]$. Titanium nitride (TiN) shows excellent chemical resistance, superior electrical conductivity, and good adhesion with most materials. Therefore, there are great interests in upgrading anode performance by doping TiN into anode matrix. Anchoring of TiN nanoparticles to graphene layers not only promotes the electrical conductivity along caxis, but also suppresses the agglomeration of graphene sheets, resulting in the formation of a flexible porous texture [7-10].

In the present study, $\mathrm{TiN}-\mathrm{C}$ nanocomposites have been prepared using benzene as a carbon source through partial decomposition under supercritical condition followed by different heat treatments under ammonia and nitrogen atmospheres. However, our previous study has revealed the formation pathway of TiN-C nanocomposites and discussed their oxygen reduction activities [10]. Regarding the importance of carbon crystalline structure and its effect on electrochemical performance, in an attempt to understand the nature of carbonaceous species, the present work is directed towards studying the respective carbon phase transitions. X-Ray Diffraction (XRD), Raman spectroscopy, Time of Flight Secondary Ion Mass Spectrometry (ToF-SIMS), and CHN elemental chemical analyses are used to identify the structure and nature of the carbonaceous species in the synthesized nanocomposites. Moreover, to confirm the obtained results, the specific capacities of the prepared nanocomposites are measured as an anode in LIBs. In the activeinactive composite of $\mathrm{C}$ and $\mathrm{TiN}, \mathrm{C}$ acts as a reactant during the lithiation process to form $\mathrm{Li}_{x} \mathrm{C}$, which is enclosed by the TiN inactive matrix. Since $\mathrm{Li}^{+}$can only intercalate into carbon layered structures, and considering the theoretical specific capacity of graphite as $372 \mathrm{mAh}^{-1}$, the specific capacity of synthesized anodes can be a representative of their structure. The TiN in the composite electrode does not alloy with lithium, but serves as an inactive matrix to support the intergrain electronic contact in the material, which would enable the TiN-C nanocomposite to exhibit good rate capability and cycling performance.

\section{Experimental}

\subsection{TiN-C nanocomposites synthesis}

TiN-C nanocomposites were synthesized by a supercritical process using benzene $\left(\mathrm{C}_{6} \mathrm{H}_{6}\right.$, Merck, $\left.99.96 \%\right)$ as a solvent and carbon source and titanium tetrachloride $\left(\mathrm{TiCl}_{4}\right.$, Merck, > 99\%) and sodium azide $\left(\mathrm{NaN}_{3}\right.$, Merck, $>99 \%$ ) as reactants at $380^{\circ} \mathrm{C}$ with the holding time of 1-8 h. Subsequently, the as-prepared sample (SI) was further heat treated at $1000^{\circ} \mathrm{C}$ for $3-10 \mathrm{~h}$ using $\mathrm{NH}_{3}$ and $\mathrm{N}_{2}$ atmospheres, as mentioned in Table 1.

\subsection{Characterization}

In order to examine the phase evolution and crystallization behavior, a STOE D-64295 diffractometer $(\mathrm{Cu}-$ $\mathrm{K} \alpha$ radiation, $\lambda=1.54056 \AA$ ) was used employing a step size of 0.015 . To evaluate the structural parameters of microcrystalite diameter $\left(L_{a}\right)$ and interlayer spacing $\left(L_{c}\right)$ for carbonaceous structure, XRD patterns were analyzed using the classical Debye-Scherer equations [11]:

$$
\begin{aligned}
& L_{c}=0.90 \lambda / \beta_{002} \cos \theta_{002}, \\
& L_{a}=1.94 \lambda / \beta_{100 / 101} \cos \theta_{100 / 101},
\end{aligned}
$$

where $\beta$ stands for Full Width at Half Maximum (FWHM) in radians of $\theta$.

In order to evaluate the nature of the crystalline structure of the carbonaceous species and the order/disorder degree of layered structure in the prepared samples, Raman spectra were taken on an ALMEGA XR Raman spectrometer at $532 \mathrm{~nm}$. The intensity, position, and width of the bands were obtained using a Gaussian curve fitting procedure. The microcrystalline diameter $\left(L_{a}\right)$ in amorphous carbons can be calculated by the following equation [12]:

$$
C(\lambda) L_{a}^{2}=\left(\frac{I_{D}}{I_{G}}\right)
$$

where $C(\lambda)$ is given to be $\sim 0.0055$ for $\lambda=514 \mathrm{~nm}$, which can be assumed as comparable with our slightly different $\lambda(532 \mathrm{~nm})$ [13]. Meanwhile, the crystallite size $\left(L_{a}\right)$ of graphene structure can be calculated by Tuinstra and Koening (TK) equation as mentioned below: 


$$
L_{a}=\left(2.4 \times 10^{-10}\right) \lambda_{\text {laser }}^{4}\left(\frac{I_{D}}{I_{G}}\right)^{-1}
$$

where $\lambda_{\text {laser }}$ denotes laser line wavelength in $\mathrm{nm}$ units. Moreover, to have better an insight into molecular reactions during supercritical process and subsequent heat treatments, ToF-SIMS analysis was carried out on the synthesized samples to study the surface chemicals with a TRIFT V, ULVAC-PHI Inc. time-of-flight secondary ion mass spectrometer equipped with a Bi liquid-metal cluster ion source. Positive and negative ion spectra were acquired with a pulsed, electrodynamically compressed 30 $\mathrm{keV}$ primary ion beam by railing the ion beam over a $16.4 \mu \mathrm{m} \times 16.4 \mu \mathrm{m}$ sample area. The primary ion dose was kept below $4.7 \times 10^{13}$ ions $/ \mathrm{cm}^{2}$ to maintain static SIMS conditions. The results were analyzed with "WinCadence N" software. The peaks were normalized to ${ }^{48} \mathrm{Ti}^{+}$and $\mathrm{CN}^{-}$peak intensities for positive and negative spectra, respectively, to correct differences in the total secondary ion yield from spectrum to spectrum, as a result of instrumental drift, and provide better comparison state between different spectra. The prepared nanocomposites were also analyzed chemically using a Yanaco CHN CORDER MT-6 carbon, hydrogen, and nitrogen analyzer to determine the amount of carbon in the samples.

\subsection{Electrochemical measurements}

The electrochemical properties of the synthesized samples were examined using a two-electrode electrochemical cell at room temperature. The working electrodes were prepared by mixing active material, and poly(vinylidene difluoride) (PVDF) binder in a weight ratio of 95:5 without adding any conductive material in NMP solvent to form a homogeneous slurry and pasted on a copper foil, and then dried in vacuum oven at $80^{\circ} \mathrm{C}$ for $12 \mathrm{~h}$. Lithium foil was used as the counter electrode and was separated from the anode by a Celgard ${ }^{\circledR}$ 2400 membrane. The electrolyte was $1.0 \mathrm{M} \mathrm{LiPF}_{6}$ in a mixture of Ethylene Carbonate (EC), dimethyl carbonate (DMC), and diethyl carbonate (DEC) with a volumetric ratio of $1: 1: 1$. The cells were charged and discharged over a voltage range of $0.005-3.0 \mathrm{~V}$ (versus $\mathrm{Li} / \mathrm{Li}^{+}$) at 0.2 C-rate using a charge-discharge unit (Hokuto Denko, HJ-1010 M) in a galvanostatic mode. Electrochemical Impedance Spectroscopy (EIS) measurements were performed using a potentionstat Ivium CompactStat by applying an AC voltage of $10 \mathrm{mV}$ amplitude in the frequency range of $10 \mathrm{mHz}-$ $100 \mathrm{kHz}$ at room temperature.

\section{Results and discussion}

\subsection{Characterization}

Figure 1 shows the XRD spectra of the powders heat treated under different conditions as mentioned in

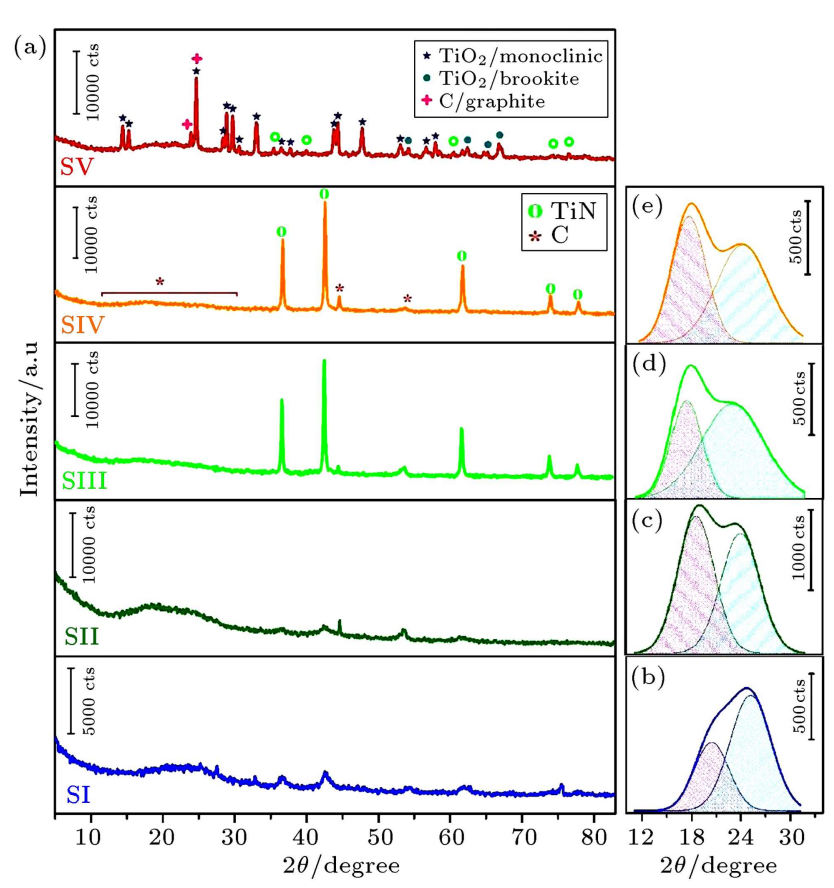

Figure 1. (a) X-ray diffraction patterns of different samples according to Table 1 and related carbon peak deconvolutions for (b) SI, (c) SII, (d) SIII, and (e) SIV samples.

Table 1. The as-prepared sample (SI) demonstrates the presence of TiN crystalline phase with characteristic peaks of $36.8^{\circ}, 42.6^{\circ}, 62.0^{\circ}$, and $74.2^{\circ}$ accompanied with carbonaceous structure. The wide (002) peak between $12-32^{\circ}$ can be deconvoluted into two peaks (Figure 1(b)-(e)), implying the existence of carbon species in turbostratic or random layer lattice structure [14]. With increasing resident time (SII), the related peak intensities, crystallite size, carbon content, and benzene decomposition into aliphatic chains raise. After $3 \mathrm{~h}$ of $\mathrm{NH}_{3}$ treatment, TiN diffraction peaks' intensities ascend sharply; consequently, the crystallite size increases from $15 \mathrm{~nm}$ up to $38 \mathrm{~nm}$. Moreover, the peaks' positions of carbonaceous species slightly shift to smaller values that indicate the phase transformation to graphene layered structure. Although further $\mathrm{NH}_{3}$ treating does not have any significant effect on TiN crystallization or crystallite size, carbon crystallization continues and microcrystalline diameter and interlayer spacing increase from $74 \mathrm{~nm}$ up to $99 \mathrm{~nm}$ and $9.23 \AA$ up to $10.90 \AA$, respectively. However, after $10 \mathrm{~h}$ of $\mathrm{N}_{2}$ treatment $(\mathrm{SV})$ at $1000^{\circ} \mathrm{C}, \mathrm{XRD}$ pattern indicates the presence of $\beta-\mathrm{TiO}_{2}$ with monoclinic structure and carbon peaks related to graphite structure.

Figure 2 shows Raman spectra of SI-SV samples and their appropriate peak deconvolution. Samples SI and SII show peaks centered at 1604, 1543, 1333, and $1231 \mathrm{~cm}^{-1}$ that are attributed to $\mathrm{G}$, amorphous carbon, $\mathrm{D}$, and $\mathrm{sp}^{3}$ rich phase, respectively $[15,16]$. The presence of wide peak at around $3000 \mathrm{~cm}^{-1}$ is 


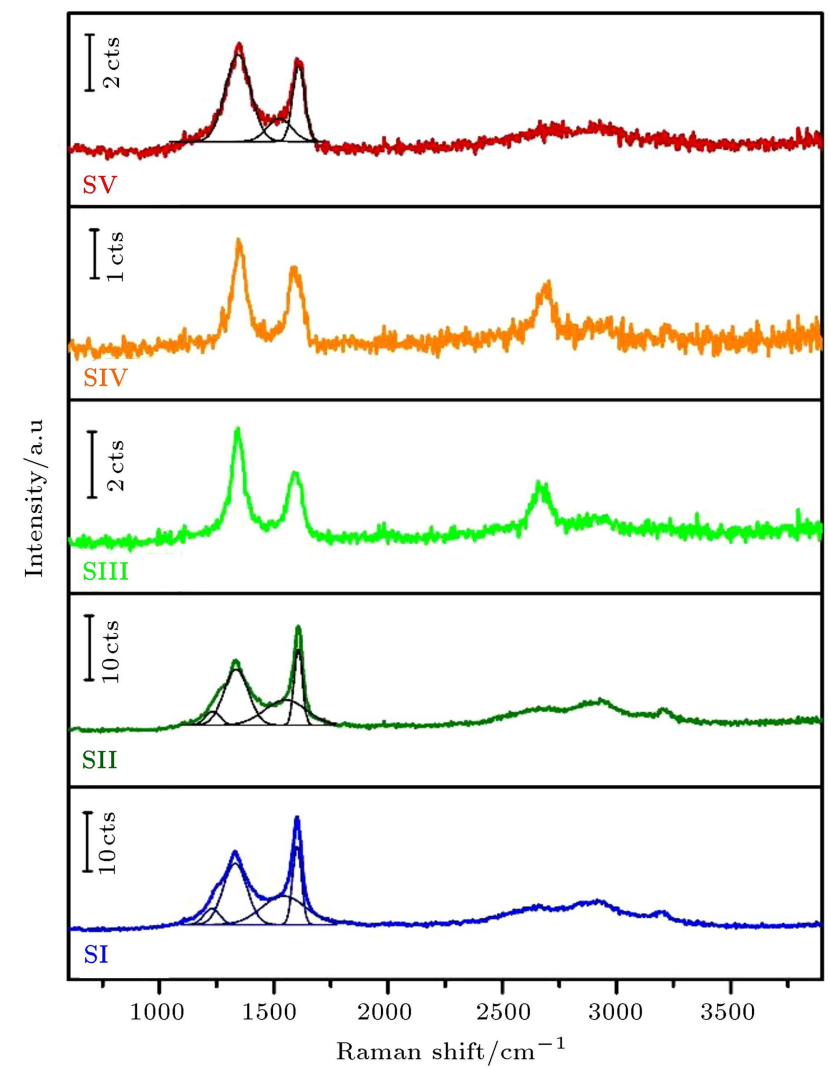

Figure 2. Raman spectra of SI-SV samples and their deconvoluted peaks.

due to amorphous carbon while small peaks at 3189 , 2914 , and $2658 \mathrm{~cm}^{-1}$ are assigned to $2 \mathrm{G}, \mathrm{D}+\mathrm{G}$, and $2 \mathrm{D}$ peaks. Regarding the literature, the presence of $\mathrm{D}, \mathrm{G}, 2 \mathrm{D}, \mathrm{D}+\mathrm{G}$, and $2 \mathrm{G}$ peaks reveals the presence of damaged graphene structure. On the other hand, the high intensity of $G$ and $D$ peaks indicates dispersed graphene layers in an amorphous carbon matrix, while wide $\mathrm{D}$ peak shows the ring order other than six for ringed $\mathrm{sp}^{2}$ carbon $[12,17]$. These data and analyses determine the carbonaceous phase structure in the asprepared samples as turbostratic or random layered lattice with $\mathrm{I}(\mathrm{D}) / \mathrm{I}(\mathrm{G})$ ratio and graphene crystallite size of 0.79 and $\sim 11 \mathrm{~nm}$, respectively. After $3 \mathrm{~h}$ of $\mathrm{NH}_{3}$ treatment, the carbon phase transforms totally to $\mathrm{sp}^{2}$ state and graphene structure. The presence of $\mathrm{G}$ peak demonstrates $\mathrm{E}_{2 g}$ mode of graphite, which is related to the vibration of $\mathrm{sp}^{2}$ bonded carbon atoms in a 2-dimensional hexagonal lattice. Meanwhile, the presence of $D$ peak is an indication of defects associated with vacancies, grain boundaries, and amorphous carbon species [18]. Moreover, the presence of $2 \mathrm{D}$ peak is the evidence of bi-layer graphene structure and good indication of $c$ axis ordering. Raman spectra with characteristic $G$ and $D$ bands are implications of defects, disorder, and carbon grain size; their intensity ratio $(\mathrm{I}(\mathrm{D}) / \mathrm{I}(\mathrm{G}))$ is related to the level of disorder degree and average size of $\mathrm{sp}^{2}$ domains $[12,19]$. In this case, the graphene crystallite size can be calculated using Eq. (4) and I(D)/I(G) = 1.68 as $~ 11$ nm. Further heat treatment leads to ring opening of $\mathrm{sp}^{2}$ atoms and subsequent decreasing of $\mathrm{I}(\mathrm{D}) / \mathrm{I}(\mathrm{G})$ ratio and increases the order degree of graphene layers. Therefore, more atoms are placed in $\mathrm{sp}^{2}$ chains, and graphene crystallite size increases to $\sim 16 \mathrm{~nm}$. The observed differences between $L_{a}$ estimated by TK and DebyeScherer equations can be related to the possibility that XRD spectrum weights are the bigger crystallites, while TK underestimates $L_{a}$ due to the dominant effect of small crystallites [12]. Thus, it can be concluded that the microcrystallite diameter of graphene patches of SIV is between $16-99 \mathrm{~nm}$.

However, heat treating under inert atmosphere leads to different structures with peaks at 1608, 1541, and $1344 \mathrm{~cm}^{-1}$. Considering the weak peak centered at $2833 \mathrm{~cm}^{-1}$ and its deconvolution, it can be concluded that SV consists of hexagonal graphitic structure with crystallite size of $\sim 17 \mathrm{~nm}$. Besides, it seems that there is still some untransformed amorphous carbons in the SV sample after $10 \mathrm{~h}$ of $\mathrm{N}_{2}$ treatment. This evidence shows the effect of reactive atmosphere on not only complement of TiN nitridation, but also on carbon phase evolution. The main reason for this is that, under ammonia atmosphere, the phase transition temperature of carbonaceous species reduces to $800^{\circ} \mathrm{C}$, while, in $\mathrm{N}_{2}$ atmosphere, this temperature will be as high as $1500^{\circ} \mathrm{C}$ [20,21]. Moreover, under $\mathrm{N}_{2}$ atmosphere, the presence of carbonaceous species prevents the crystallization and growth of the TiN crystals during heat treatment [22].

To have more understanding on the supercritical process reactions and the following heat treatment mechanism, the chemical state of the synthesized powders was investigated by positive/negative ion ToFSIMS analysis. Figure 3 represents positive ToF-SIMS spectra of different samples with the most intense peak of ${ }^{48} \mathrm{Ti}^{+}$at $\mathrm{m} / \mathrm{z}$ of $47.95 \mathrm{u}$. All $\mathrm{Ti}$ isotopes are also seen in the ToF-SIMS patterns. Moreover, the peaks at $61.95,63.94$, and 64.95 assigned to ${ }^{48} \mathrm{TiN}^{+}$, ${ }^{48} \mathrm{TiO}^{+}$, and ${ }^{48} \mathrm{TiOH}^{+}$ion fragments, respectively, are significantly intense as well. Meanwhile, the isotopes of these compounds experience some overlaps. The peaks at 59.96 and 60.96 are assigned to ${ }^{46} \mathrm{TiN}^{+}$and ${ }^{47} \mathrm{TiN}^{+}$ion fragments, respectively. Meanwhile, the peak at 61.95 relates to ${ }^{48} \mathrm{TiN}^{+}$and ${ }^{46} \mathrm{TiO}^{+}$fragments. The peak at 62.96 corresponds to ${ }^{49} \mathrm{TiN}^{+},{ }^{47} \mathrm{TiO}^{+}$, and ${ }^{46} \mathrm{TiOH}^{+}$. Further, the peak at 63.95 relates to ${ }^{50} \mathrm{TiN}^{+},{ }^{48} \mathrm{TiO}^{+}$, and ${ }^{47} \mathrm{TiOH}^{+}$. The peak at 64.95 stands for ${ }^{49} \mathrm{TiO}^{+}$and ${ }^{48} \mathrm{TiOH}^{+}$and the peak at 65.96 reveals ${ }^{50} \mathrm{TiO}^{+}$and ${ }^{49} \mathrm{TiOH}^{+}$. Moreover, the peak at 66.96 assigns to ${ }^{50} \mathrm{TiOH}^{+}$ion fragment. The relative intensity of each compound in the overlapped peaks can be calculated based on $\mathrm{Ti}$ isotopes distribution. The presence of oxygen, which is always detected, is due to 


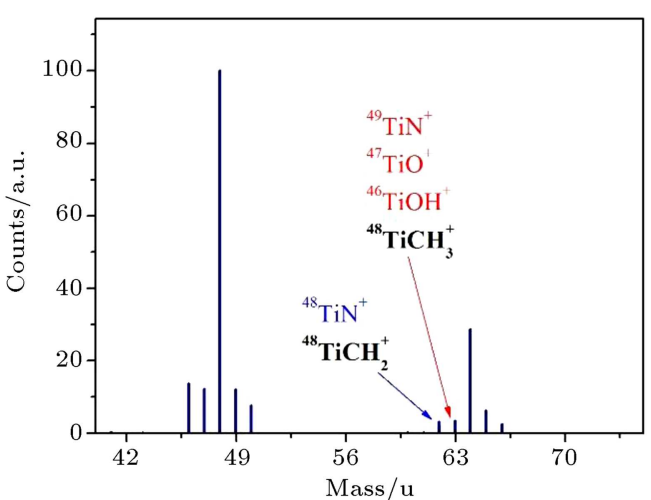

(a) SI

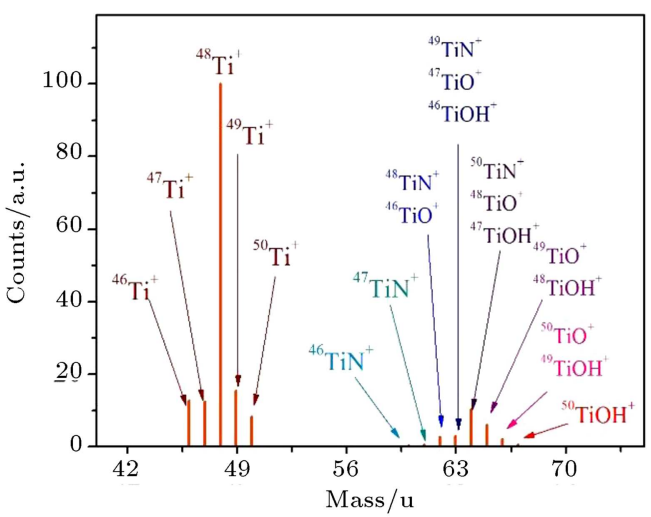

(c) SIV

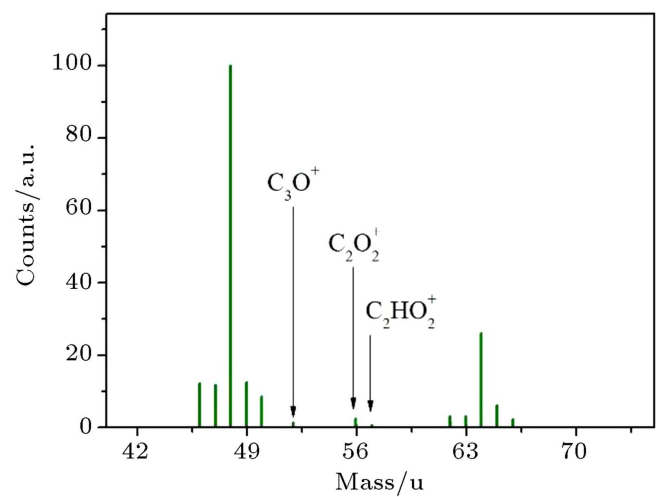

(b) SII

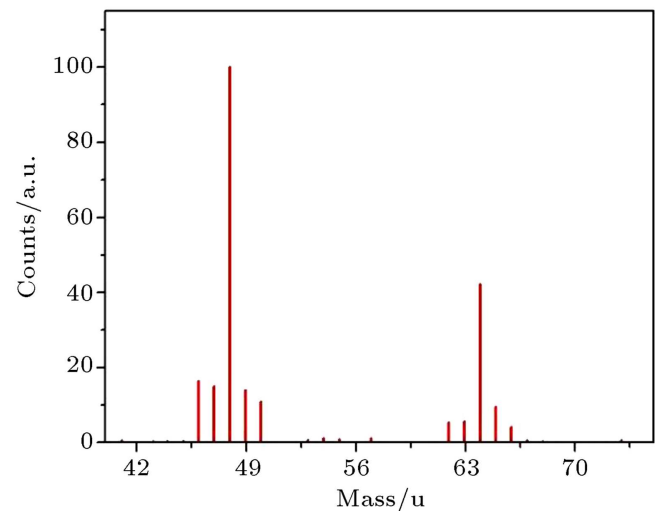

(d) $\mathrm{SV}$

Figure 3. Positive ion ToF-SIMS spectra of the synthesized TiN-C nanocomposites by different conditions: (a) SI, (b) SII, (c) SIV, and (d) SV.

moisture or oxygen uptake during air exposure after the synthesis process and/or oxygen or water released from the water in the washing step. The remaining amount of Ti-O bonds which are in amorphous state according to XRD patterns is unavoidable due to partial surface oxidation of TiN compounds after heat treatment. The characteristic peaks of the analyzed precursor and their assignments are demonstrated in Figure 3. By comparing the positive ion spectra of the precursors synthesized for 1 (SI) and $8 \mathrm{~h}$ (SII), increasing resident time mostly leads to formation of carbide species and increasing relative intensity of some other compounds such as $\mathrm{CHN}, \mathrm{C}_{2} \mathrm{O}_{2}$, and $\mathrm{HNO}_{2}$. However, the benzene molecular ion (i.e., $\mathrm{C}_{6} \mathrm{H}_{5} \mathrm{Ti}$ expected at $124.99 \mathrm{~m} / \mathrm{z}$ ) was not detected, but the presence of some organic compounds on the surface of the precursor would attest to benzene partial decomposition under supercritical condition and subsequent reacting with azide groups and formation of $\mathrm{C}-\mathrm{H}, \mathrm{C}-\mathrm{H}-\mathrm{N}$ or $\mathrm{C}_{2} \mathrm{H}_{4} \mathrm{~N}$ bonds on the surface of the precursor. According to this observation, benzene decomposition and its reaction with azide groups and titanium tetrachloride would be increased with rising holding time. It is worth mentioning that some compounds, such as $\mathrm{TiCH}_{3}$, in the ToF-SIMS spectra of the as-prepared precursor with weak peak intensity are detected which represent the benzene circles broken and that consequent hydrocarbons react with $\mathrm{TiCl}_{4}$. The ToF-SIMS data indicate some organic functional groups existing on the surface of the precursor.

After applying heat treatment, almost all functional groups, such as $\mathrm{C}-\mathrm{H}$ bands and $\mathrm{NO}_{2}$ groups, on the surface of as-prepared precursor are removed. Moreover, it can be seen that, after heat treatment, the relative peak intensities of $\mathrm{TiO}, \mathrm{TiOH}$, and $\mathrm{TiCH}_{x}$ bonds decrease. The remaining amount of oxide bonds is unavoidable due to partial surface oxidizing of TiN compounds. As well, SIMS data do not expose any other important difference between chemical composition of $\mathrm{NH}_{3}$ treated samples for $3 \mathrm{~h}$ and $10 \mathrm{~h}$. However, SV shows more intense $\mathrm{TiO}$ peak, in addition to some small peaks that are assigned to oxynitride/carbonitride species.

To have a better understanding on the carbon ion species and phase evolutions, the negative ToF-SIMS spectra of SI and SIV samples and the related peak assignments are shown in Figure 4. Carbon bonding states are present in $\mathrm{sp}^{2}$ and $\mathrm{sp}^{3}$ of $\mathrm{C}^{-}, \mathrm{C}_{2}^{-}, \mathrm{C}_{3}^{-}$, $\mathrm{C}_{4}^{-}$, and $\mathrm{C}_{6}^{-}$at $\mathrm{m} / \mathrm{z}$ of $12.00,24.00,36.00,48.00$, and $72.00 \mathrm{u}$, respectively, while the highest intensity results from $\mathrm{C}_{2}^{-}$. The presence of $\mathrm{CN}^{-}$ion mass fragment in the $\mathrm{SI}$ reveals the incorporation of $\mathrm{N}$ into carbon 

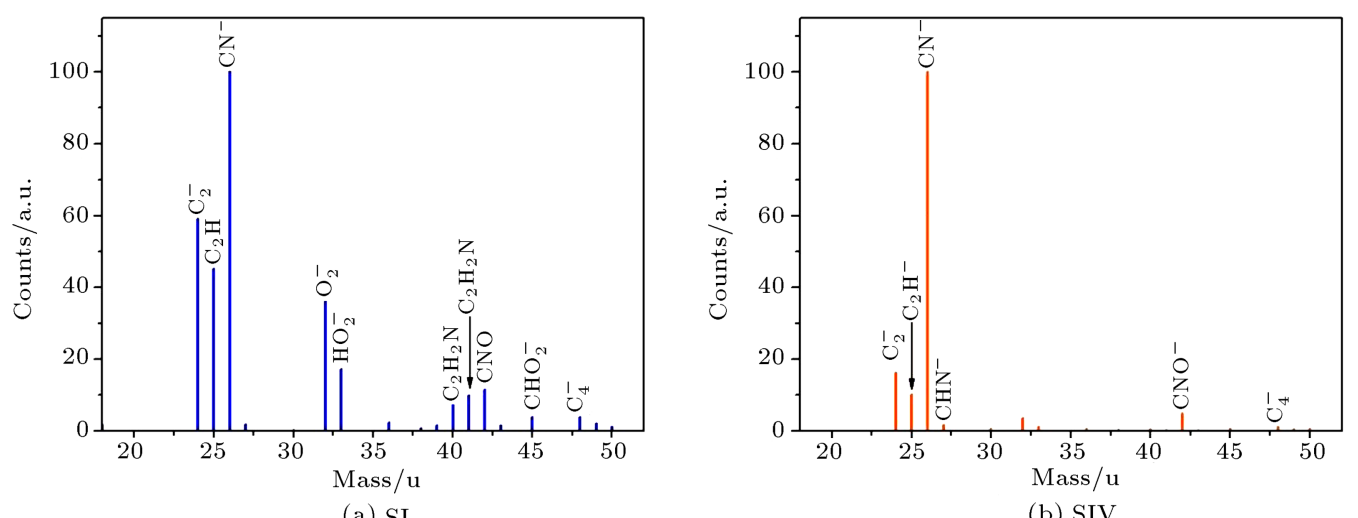

Figure 4. Negative ion ToF-SIMS spectra of the synthesized TiN-C nanocomposites by different conditions: (a) SI and (b) SIV.

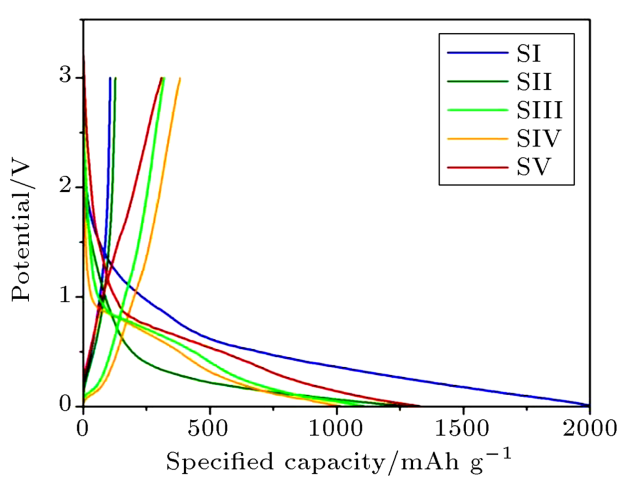

(a)

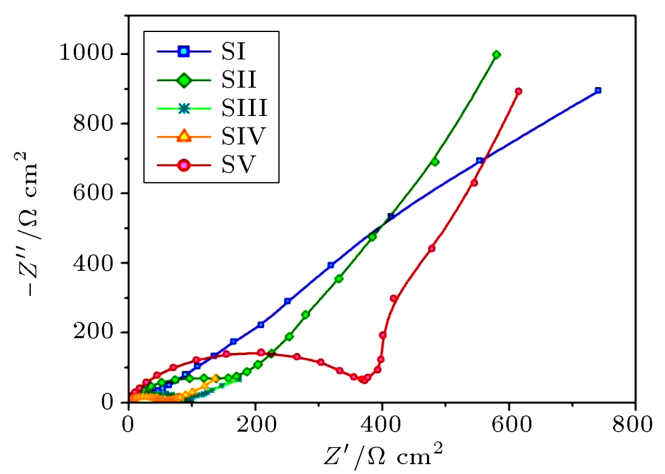

(b)

Figure 5. Electrochemical performance of the synthesized samples as anode in $1 \mathrm{M} \mathrm{LiPF}_{6}$-EC:DMC:DEC (vol. 1:1:1) electrolyte: (a) First C/D curves cycled at $0.2 \mathrm{C}$ between 3 and $0.005 \mathrm{~V}$ vs. $\mathrm{Li} / \mathrm{Li}^{+}$, and (b) Nyquist plots at $3.0 \mathrm{~V}$ vs. $\mathrm{Li} / \mathrm{Li}^{+}$before cycling.

lattice, meaning that azide groups are a nitrogen source for both $\mathrm{Ti}$ and carbon atoms. After $10 \mathrm{~h}$ of $\mathrm{NH}_{3}$ treating at $1000^{\circ} \mathrm{C}$, the peak intensity of $\mathrm{CN}^{-}$ion fragment increases around 6 times. The doped nitrogen would affect the graphene properties and performance. At first, it would disrupt $\mathrm{sp}^{2}$ hybridization of carbon atoms and affect electronic properties [23]. Moreover, it would enhance carrier density and, consequently, increase the conductivity of graphene [24]. Finally, it would remarkably increase the graphene specific capacitance [25]. The presence of some $\mathrm{CH}$ and $\mathrm{CHN}$ compounds in the negative SIMS spectra of SIV can be attributed to the presence of saturated structures, such aliphatic side chains, attached to the edge of the carbon crystallites.

To have a more accurate comprehension on the chemical composition of the synthesized TiN-C nanocomposites, and specially provide a quantitative measure of the carbon contain, CHN analysis was conducted and the results are shown in Table 2 .

\subsection{Electrochemical performance}

To determine the electrochemical performances of the synthesized TiN-C nanocomposites as anodes in LIB,
Table 2. Elemental analysis of various samples prepared in different conditions.

\begin{tabular}{cccc}
\hline Sample & C (wt\%) & H (wt\%) & N (wt\%) \\
\hline SI & 41.66 & 2.28 & 2.51 \\
SII & 50.12 & 2.37 & 3.10 \\
SIII & 44.08 & 1.40 & 10.06 \\
SIV & 35.99 & 0.67 & 10.78 \\
SV & 16.89 & 0.42 & 1.26 \\
\hline
\end{tabular}

galvanostatic $\mathrm{C} / \mathrm{D}$ cycles have been performed at a rate of $0.2 \mathrm{C}$ over a potential range of $0.005-3.0 \mathrm{~V}$ (versus $\mathrm{Li} / \mathrm{Li}^{+}$), shown in Figure 5(a). The calculated specific capacities are obtained based on $\mathrm{C}$ mass as active material. The synthesized samples SI, SII, SIII, SIV, and SV demonstrate specific capacity of 105, 125, 317, 381 , and $307 \mathrm{mAh}^{-1}$ with columbic efficiency of 5 , $10,29,38$, and $23 \%$, respectively. These results confirm the characterization analysis and show the existence of random layered structure in the as-prepared samples. The specific capacities of SI and SII samples that are 0.28 and 0.34 of theoretical specific capacity of graphite structure, respectively, reveal that the carbon has a random layered structure in these nanocomposites 


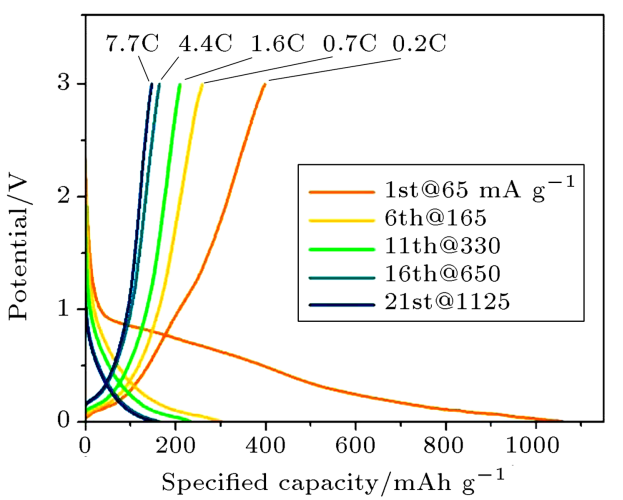

(a)

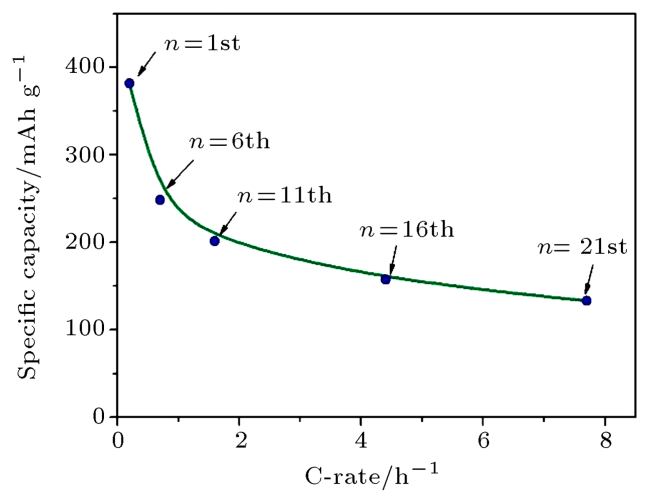

(b)

Figure 6. Electrochemical performance of the TiN/G nanocomposite as anode in $1 \mathrm{M} \mathrm{LiPF}_{6}$-EC:DMC:DEC (vol. 1:1:1) electrolyte cycled between 3 and $0.005 \mathrm{~V}$ vs. Li $/ \mathrm{Li}^{+}:$(a) $\mathrm{C} / \mathrm{D}$ curves cycled with different rates as $n=1$ st $\sim 5$ th @ $0.2 \mathrm{C}, n$ $=6$ th $\sim 10$ th @ $0.7 \mathrm{C}, n=11 \mathrm{th} \sim 15 \mathrm{th} @ 1.6 \mathrm{C}, n=16 \mathrm{th} \sim 20 @ 4.4 \mathrm{C}$, and $n=21 \mathrm{st} \sim 25 @ 7.7$ C-rate, and (b) the specific capacity as a function of $\mathrm{C} / \mathrm{D}$ rate.

that is in accordance with XRD and Raman analysis. Moreover, increasing resident time not only leads to more benzene decomposition, but also helps for more carbon crystallization. Increasing $\mathrm{NH}_{3}$ treating time leads to ordering graphene structure and, consequently, improving electrochemical performance of SIV compare with SIII. The specific capacity of SV sample is 0.83 of theoretical specific capacity of graphite structure that confirms the existence of an amorphous phase with graphite structure. It is apparent that all TiN$\mathrm{C}$ nanocomposites showing a huge irreversible capacity loss on the first cycle can be attributed to: (1) the incapability of removing all the lithium on discharge that is inserted onto the first charge; (2) the reduction of the electrolyte on the electrode surface and formation of Solid Electrolyte Interface (SEI) [26-29]. Li ions can be trapped into graphene defect sites because of reacting with surface functional groups [30-32]. The EIS measurements that have been done before cycling at $3.0 \mathrm{~V}$ versus $\mathrm{Li} / \mathrm{Li}^{+}$and the corresponding Nyquist plots are shown in Figure 5(b), indicating that the impedance of samples reduces with the application of heat treatment because of crystallization of both TiN and $\mathrm{C}$ phases. Moreover, TiN nanoparticles increase conductivity of SIV and, consequently, lead to the decrease of the impedance compared with SV sample. These results show that anchoring of TiN nanoparticles on $\mathrm{G}$ sheets enhances the electrochemical performance by improving the electronic/ionic conductivity, reducing charge transfer coefficient, and increasing electrochemical surface area. Based on these analyses, under supercritical condition with temperature as low as 380 ${ }^{\circ} \mathrm{C}$ and pressure around 150 atm., the carbonaceous phase with random layered structure is achievable. After applying $\mathrm{NH}_{3}$ treating, the carbon phase transforms into graphene-layered structure. Meanwhile, increasing heat treatment time, mostly, leads to growing up and ordering of graphene layers.
Considering the notable specific capacity of SIV, its electrochemical performance is further investigated. In this regard, galvanostatic C/D cycles have been performed at different rates (Figure 6(a)), and the corresponding relationship between the specific capacities and the current densities acquired from the C/D curves in Figure 6(a) are depicted in Figure 6(b). The $\mathrm{TiN} / \mathrm{G}$ nanocomposite conveys a specific capacity of $381 \mathrm{mAh} \mathrm{g}^{-1}$ at a current density of $0.2 \mathrm{C}$. Meanwhile, at higher current density of $7.7 \mathrm{C}$, a remarkable specific capacity of $133 \mathrm{mAh} \mathrm{g}^{-1}$ is also delivered that represents a good rate capability. It is worth noting that the specific capacity of $\mathrm{G}$ in $\mathrm{TiN} / \mathrm{G}$ nanocomposites increases as a function of $\mathrm{G}$ in proportion up to 641 $\mathrm{mAh} \mathrm{g}^{-1}$ at $65 \% \mathrm{G}[7,8]$. Afterwards, the extra addition of $\mathrm{G}$ leads to decreasing the specific capacity of $\mathrm{G}$ to $218 \mathrm{mAh} \mathrm{g}^{-1}$ at $82 \% \mathrm{G}$ with $\mathrm{C} / \mathrm{D}$ rate of $0.5 \mathrm{C}$, which is almost equal to $\mathrm{G}$ performance. The synthesized TiN/G nanocomposite with $36 \% \mathrm{G}$ and a specific capacity of $254 \mathrm{mAh} \mathrm{g}^{-1}$ are in accordance with the provided trend that suggests comparable quality of $\mathrm{G}$ sheets. The decrease of specific capacity in low content TiN composites may ascribe to the insufficient cover of TiN on $\mathrm{G}$ that leads to producing large amount of SEI on the surface of electrode. Meanwhile, the decrease of specific capacity in composites with high amounts of TiN is due to the excess inactive TiN that reduces the reversible capacitance. Using supercritical process to fabricate $\mathrm{TiN} / \mathrm{G}$ nanocomposite, the percentage of $\mathrm{G}$ that is a function of benzene decomposition can be controlled by process time [10] and temperature [33].

According to differential capacity analysis, as depicted in Figure 7 , there are different $\mathrm{Li}$ storage sites in the synthesized $\mathrm{TiN} / \mathrm{G}$ anode that could be divided into three areas, namely below 0.5 , between $0.5-1.3$, and above $1.3 \mathrm{~V}$ versus $\mathrm{Li} / \mathrm{Li}^{+}$. Three pairs of reversible peaks below $0.5 \mathrm{~V}$ versus $\mathrm{Li} / \mathrm{Li}^{+}$are due to lithium insertion into the graphene layers [34,35]. 


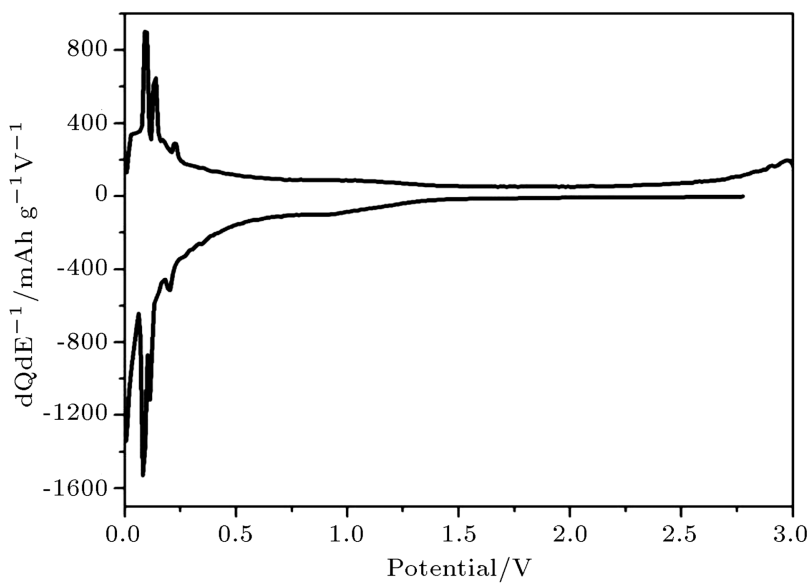

Figure 7. Derivative $\mathrm{dx} / \mathrm{dV}$ plotted vs. voltage of the 30th cycle of TiN/G electrode cycled between 3 and 0.005 $\mathrm{V}$ vs. $\mathrm{Li} / \mathrm{Li}^{+}$at $\mathrm{C} / 25$.

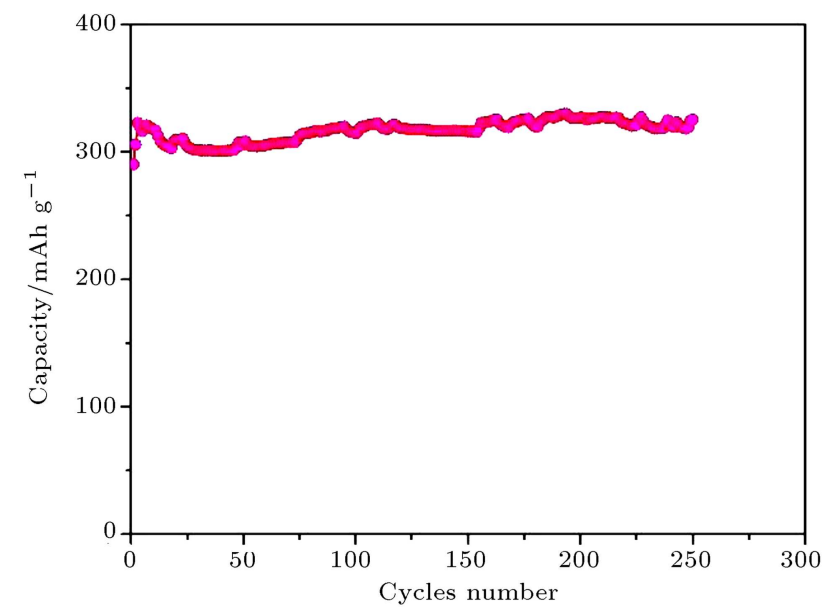

Figure 8. Cycling performance at 1.6 C-rate using $\mathrm{TiN} / \mathrm{G}$ electrode as an anode material.

On the other hand, between $0.5-1.3 \mathrm{~V}$ versus $\mathrm{Li} / \mathrm{Li}^{+}$, lithium ions are intercalated into micropores, while double-layer mechanism is the prominent phenomenon at higher potentials.

The TiN/G demonstrates good cycling behavior as indicated in Figure 8. At first, specific capacity initially increases up to 1.1 times during the first three cycles that can be attributed to the boosting of its porous network structure. During $\mathrm{Li}$ insertion and extraction process, in the initial cycles, the TiN clusters pulverize into small particles due to electrochemical milling effects that lead to more porous nanostructures with more edges, which are able to provide more activated sites for $\mathrm{Li}$ storage and also facilitate the penetration of the electrolytes $[18,36]$. Establishing diffusive condition because of SEI formation leads to a capacity retention $(\mathrm{C} 15 / \mathrm{C} 3)$ of $95 \%$. Afterwards, the capacity starts to ascend due to gradual extraction of trapped $\mathrm{Li}$ ions into SEI or cavities [37] in such a way that shows capacity retention of $112 \%$ after 250 cycles. Actually, it seems that the larger number of lithiation/delithiation cycles activates electrochemical processes associated to the diffusion of $\mathrm{Li}^{+}$that allows the trapped $\mathrm{Li}^{+}$to be gradually extracted from the micropores, and so the capacity increases.

\section{Conclusion}

TiN-C nanoparticles were synthesized using $\mathrm{TiCl}_{4}$ and $\mathrm{NaN}_{3}$ reactants in supercritical benzene medium that also serves as a carbon source and, afterward, applies heat treatment under $\mathrm{NH}_{3}$ and $\mathrm{N}_{2}$ atmospheres. The evolutions of carbon phase during supercritical process and following heat treatments were studied extensively. After $10 \mathrm{~h}$ of $\mathrm{NH}_{3}$ treating at $1000^{\circ} \mathrm{C}$, amorphous carbon was transferred to $\mathrm{N}$-doped graphene structure, while $\mathrm{N}_{2}$ treating led to a different structure. The synthesized nanoparticles were tested as anodes for LIBs. The TiN/G material exhibited superior electrochemical performance as an anode for LIBs with specific capacities of 381 and $133 \mathrm{mAh} \mathrm{g}^{-1}$ at $\mathrm{C} / \mathrm{D}$ rates of 0.2 and $7.7 \mathrm{C}$, respectively. Meanwhile, TiN/G electrode depicts the capacity retention of $99 \%$ after 250 cycles at $\mathrm{C} / \mathrm{D}$ rate of $0.7 \mathrm{C}$. The favorable electrochemical performance of $\mathrm{TiN} / \mathrm{G}$ anode is related to the highly efficient mixed conducting network and doping nitrogen into graphene sheets, improving the electronic/ionic conductivity, reducing charge transfer coefficient, and increasing electrochemical surface area. The introduced facile synthesis of TiN/G nanocomposite provides an advantageous pathway towards the development of high energy density, long cycle life, and commercial Li-ion anodes by anchoring of TiN nanoparticles to $\mathrm{G}$ that promotes energy storage applications in high-performance lithium-ion batteries.

\section{Acknowledgement}

The authors are grateful for the partial financial support of this study by research council of Sharif University of Technology. Moreover, authors would like to thank Ms. M. Watanabe for worthwhile helps about ToF-SIMS experiments.

\section{References}

1. Pan, D., Wang, S., Zhao, B., Wu, M., Zhang, H., Wang, Y. and Jiao, Z. "Li storage properties of disordered graphene nanosheets", Chem. Mater., 21(14), pp. 3136-3142 (2009).

2. Xiang, H.F., Li, Z.D., Xie, K., Jiang, J.Z., Chen, J.J., Lian, P.C., Wu, J.S., Yu, Y. and Wang, H.H. "Graphene sheets as anode materials for Li-ion batteries: preparation, structure, electrochemical properties and mechanism for lithium storage", RSC Adv., 2(17), pp. 6792-6799 (2012). 
3. Wang, H., Zhang, C., Liu, Z., Wang, L., Han, P., Xu, H., Zhang, K., Dong, S., Yao, J. and Cui, G. "Nitrogen-doped graphene nanosheets with excellent lithium storage properties", J. Mater. Chem., 21(14), pp. 5430-5434 (2011).

4. Chen, M.-H., Wu, G.-T., Zhu, G.-M., You, J.-K. and Lin, Z.-G. "Characterization and electrochemical investigation of boron-doped mesocarbon microbead anode materials for lithium ion batteries", J. Solid State Electrochem., 6(6), pp. 420-427 (2002).

5. Kim, S.-J., Park, H.-C., Kim, M.-C., Kim, D.-M., Lee, Y.-W. and Park, K.-W. "Sputtered amorphous thin film nanocomposites as an anode for lithium-ion batteries", J. Power Sources, 273, pp. 707-715 (2015).

6. Yan, C., Xi, W., Si, W., Deng, J. and Schmidt, O.G. "Highly conductive and strain-released hybrid multilayer Ge/Ti nanomembranes with enhanced lithiumion-storage capability", Adv. Mater., 25(4), pp. 539544 (2013).

7. Yue, Y., Han, P., He, X., Zhang, K., Liu, Z., Zhang, C., Dong, S., Gu, L. and Cui, G. "In situ synthesis of a graphene/titanium nitride hybrid material with highly improved performance for lithium storage", J. Mater. Chem., 22(11), pp. 4938-4943 (2011).

8. Han, P., Yue, Y., Wang, X., Ma, W., Dong, S., Zhang, K., Zhang, C. and Cui, G. "Graphene nanosheettitanium nitride nanocomposite for high performance electrochemical capacitors without extra conductive agent addition", J. Mater. Chem., 22(47), pp. 2491824923 (2012).

9. Lu, X., Wei, H., Chiu, H.-C., Gauvin, R., Hovington, P., Guerfi, A., Zaghib, K. and Demopoulos, G.P. "Rate-dependent phase transitions in $\mathrm{Li}_{2} \mathrm{FeSiO}_{4}$ cathode nanocrystals", Sci. Rep., 5, p. 8599 (2015).

10. Yousefi, E., Ghorbani, M., Dolati, A., Yashiro, H. and Outokesh, M. "Preparation of new titanium nitridecarbon nanocomposites in supercritical benzene and their oxygen reduction activity in alkaline medium", Electrochim. Acta, 164, pp. 114-124 (2015).

11. Sakintuna, B., Yurum, Y. and Cetinkaya, S. "Evolution of carbon microstructures during the pyrolysis of Turkish elbistan lignite in the temperature range 700$1000^{\circ}$ C", Energy Fuels, 18(3), pp. 883-888 (2004).

12. Ferrari, A.C. "Raman spectroscopy of graphene and graphite: Disorder, electron-phonon coupling, doping and nonadiabatic effects", Solid State Commun., 143(1-2), pp. 47-57 (2007).

13. Childres, I., Jauregui, L.A., Park, W., Cao, H. and Chen, Y.P. "Raman spectroscopy of graphene and related materials", In New Developments in Photon and Materials Research, Jang, J. I., Ed., pp. 1-20, Nova Science Publishers, New York (2013).

14. Manoj, B. and Kunjomana, A.G. "Study of stacking structure of amorphous carbon by X-ray diffraction technique", Int. J. Electrochem. Sci., 7, pp. 3127-3134 (2012).
15. Jorio, A., Saito, R., Dresselhaus, G. and Dresselhaus, M.S. "Raman spectroscopy: from graphite to $\mathrm{sp}^{2}$ nanocarbons", In Raman Spectroscopy in Graphene Related Systems, pp. 73-101, Wiley-VCH Verlag GmbH \& Co. KGaA (2011).

16. Pimenta, M.A., Dresselhaus, G., Dresselhaus, M.S., Cancado, L.G., Jorio, A. and Saito, R. "Studying disorder in graphite-based systems by Raman spectroscopy", Phys. Chem. Chem. Phys., 9(11), pp. 12761290 (2007).

17. Ferrari, A.C. and Robertson, J. "Raman spectroscopy of amorphous, nanostructured, diamond-like carbon, and nanodiamond", Phil. Trans. R. Soc. A, 362(1824), pp. 2477-2512 (2004).

18. Liu, L., An, M., Yang, P. and Zhang, J. "Superior cycle performance and high reversible capacity of $\mathrm{SnO}_{2}$ /graphene composite as an anode material for lithium-ion batteries", Sci. Rep., 5, p. 9055 (2015).

19. Tamuleviciene, A., Kopustinskas, V., Niaura, G., Meskinis, S. and Tamulevicius, S. "Multiwave length Raman analysis of $\mathrm{SiO}_{x}$ and $\mathrm{N}$ containing amorphous diamond like carbon films", Thin Solid Films, 581, pp. 86-91 (2015).

20. Cui, T., Lv, R., Huang, Z.-H., Zhu, H., Jia, Y., Chen, Sh., Wang, K., Wu, D. and Kang, F. "Low-temperature synthesis of multilayer graphene/amorphous carbon hybrid films and their potential application in solar cells", Nanoscale Res. Lett., 7, p. 453 (2012).

21. Barreiro, A., Borrnert, F., Avdoshenko, S.M., Rellinghaus, B., Cuniberti, G., Rummeli, M.H. and Vandersypen, L.M.K. "Understanding the catalyst-free transformation of amorphous carbon into graphene by current-induced annealing", Sci. Rep., 3, p. 1115 (2013).

22. Kim, I.-S. and Kumta, P.N. "Hydrazide sol-gel synthesis of nanostructured titanium nitride: precursor chemistry and phase evolution", J. Mater. Chem., 13, pp. 2028-2035 (2003).

23. D'Souza, F. and Kadish, K.M., Handbook of Carbon Nano Materials: (in 2 volumes) Volume 5: GrapheneFundamental Properties Volume 6: Graphene-Energy and Sensor Applications, p. 552, World Scientific (2014).

24. Pu, N.-W., Peng, Y.-Y., Wang, P.-C., Chen, C.-Y., Shi, J.-N., Liu, Y.-M., Ger, M.-D. and Chang, C.-L. "Application of nitrogen-doped graphene nanosheets in electrically conductive adhesives", Carbon, 67, pp. 449-456 (2014).

25. Kumar, M.P., Kesavan, T., Kalita, G., Ragupathy, P., Narayanan, T.N. and Pattanayak, D.K. "On the large capacitance of nitrogen doped graphene derived by a facile route", $R S C A d v$., 4(73), pp. 38689-38697 (2014).

26. Aurbach, D., Markovsky, B., Weissman, I., Levi, E. and Ein-Eli, Y. "On the correlation between surface chemistry and performance of graphite negative elec- 
trodes for Li ion batteries", Electrochim. Acta, 45(1-2), pp. 67-86 (1999).

27. Beguin, F., Chevallier, F., Vix, C., Saadallah, S., Rouzaud, J.N. and Frackowiak, E. "A better understanding of the irreversible lithium insertion mechanisms in disordered carbons", J. Phys. Chem. Solids, 65(2-3), pp. 211-217 (2004).

28. Verma, P., Maire, P. and Novak, P. "A review of the features and analyses of the solid electrolyte interphase in Li-ion batteries", Electrochim. Acta, 55(22), pp. 6332-6341 (2010).

29. Yan, Z., Liu, L., Guo, H., Tan, J., Shu, H., Yang, X., Hu, H., Zhou, Q., Huang, Z. and Wang, X. "Onepot synthesis of FCNTs-wired $\mathrm{TiO}_{2}$ nanocomposites as anode materials for high-rate lithium ion batteries", Electrochim. Acta, 123, pp. 551-559 (2014).

30. Lee, S.W., Yabuuchi, N., Gallant, B.M., Chen, S., Kim, B.-S., Hammond, P.T. and Shao-Horn, Y. "Highpower lithium batteries from functionalized carbonnanotube electrodes", Nat. Nanotechnol., 5(7), pp. 531-537 (2010).

31. Yoo, E., Kim, J., Hosono, E., Zhou, H.-S., Kudo, T. and Honma, I. "Large reversible Li storage of graphene nanosheet families for use in rechargeable lithium ion batteries", Nano Lett., 8(8), pp. 2277-2282 (2008).

32. Han, X., Chang, C., Yuan, L., Sun, T. and Sun, J. "Aromatic carbonyl derivative polymers as highperformance Li-ion storage materials", Adv. Mater., 19(12), pp. 1616-1621 (2007).

33. Hu, J., Lu, Q., Tang, K., Yu, S., Qian, Y., Zhou, G. and Liu, X. "Low-Temperature Synthesis of Nanocrystalline Titanium Nitride via a BenzeneThermal Route", J. Am. Ceram. Soc., 83(2), pp. 43032 (2000).

34. Wang, H. and Yoshio, M. "Carbon-coated natural graphite prepared by thermal vapor decomposition process, a candidate anode material for lithium-ion battery", J. Power Sources, 93(1-2), pp. 123-129 (2001).

35. Xiao, X., Liu, P., Wang, J.S., Verbrugge, M.W. and Balogh, M.P. "Vertically aligned graphene electrode for lithium ion battery with high rate capability", Electrochem. Commun., 13(2), pp. 209-212 (2011).

36. Chen, Y., Song, B., Chen, R.M., Lu, L. and Xue, J. "A study of the superior electrochemical performance of $3 \mathrm{~nm} \mathrm{SnO}_{2}$ nanoparticles supported by graphene", J. Mater. Chem. A, 2(16), pp. 5688-5695 (2014).

37. Pereira, N., Dupont, L., Tarascon, J.M., Klein, L.C. and Amatucci, G.G. "Electrochemistry of $\mathrm{Cu}_{3} \mathrm{~N}$ with lithium: A complex system with parallel processes", J. Electrochem. Soc., 150(9), pp. A1273A1280 (2003).

\section{Biographies}

Elahe Yousefi is a $\mathrm{PhD}$ Candidate in the Department of Material Science and Engineering at Sharif University of Technology in Tehran, Iran. She received her bachelor (2008) and master (2010) degrees from Tehran Polytechnic and Sharif Universities, respectively. Her research covers a variety of electrochemical problems including synthesis of electrocatalysts, electrodeposition and electrophoretic and respective mechanistic studies, improving anodes performance in Li-ion batteries, fuel cells catalysts and reactions, and their related mechanisms.

Mohammad Ghorbani is a Full Professor at the Department of Material Science and Engineering at Sharif University of Technology in Tehran, Iran. He earned his Master (1986) and Doctoral (1991) degrees from Manchester University, UMIST, UK. His research covers a variety of coatings included in electrodeposition of metallic coatings, composite coatings, conversion coatings, and nano coatings that lead to the publication of more than one hundred ISI papers.

Abolghasem Dolati is a Full Professor at the Department of Material Science and Engineering at Sharif University of Technology in Tehran, Iran. He earned his Master (1995) and Doctoral (2003) degrees from Sharif University of Technology. His research covers a variety of electrochemical issues including electrodeposition of thin films, composites \& nanomaterials, kinetics of metals \& alloys electrodeposition, modeling \& simulation of electrodeposition, and corrosion \& protection of materials. In these respects, he has published more than one hundred ISI papers.

Hitoshi Yashiro is a Full Professor at the Department of Chemistry and Bioengineering at Iwate University in Morioka, Japan. He earned his Bachelor (1982) and Doctoral (1994) degrees from Tohoku University. He was an international fellow at SRI International in 1991-1992. His research covers a variety of corrosion problems ranging from lithium ion battery to nuclear power plants. He served as an Editor-in-Chief for Japan Society of Corrosion Engineering in 2009-2011. 